\title{
GEOTECHNICAL PROPERTIES OF SALT MARSH AND TIDAL FLAT SUBSTRATES AT TILLINGHAM, ESSEX, UK.
}

\author{
Helen Brooks ${ }^{1}$, Iris Möller ${ }^{1}$, Tom Spencer ${ }^{1}$, Kate Royse $^{2}$ and Simon James Price ${ }^{3}$
}

\begin{abstract}
Salt marshes and, to a lesser extent, tidal flats, attenuate incoming hydrodynamic energy, thus reducing flood and erosion risk in the coastal hinterland. However, marshes are declining in aerial extent both globally and regionally (e.g. the Northwest European region). In order to comprehend why a reduction in salt marsh extent due to marsh edge erosion is occurring, we need to understand the resistance of salt marshes to incoming hydrodynamic energy. This resistance depends on marsh biological, geochemical and geotechnical properties. However, there currently exists no systematic study of marsh geotechnical properties and how these may impact both marsh edge and marsh surface erosion processes (e.g. surface removal, cliff undercutting, gravitational slumping). This has led to an oversimplification of marsh evolution models. Here, we present the initial results of a systematic study of salt marsh and tidal flat geotechnical properties (shear strength, plasticity and particle size) at Tillingham marsh, Essex, UK.
\end{abstract}

Keywords: salt marsh; tidal flat; geotechnical properties; shear strength; nature-based coastal protection; coastal defense

\section{INTRODUCTION}

\section{Background}

Salt marshes and tidal flats attenuate incoming waves, tidal and storm surge-induced currents. As such, marshes and tidal flats have a nature-based coastal defense value and, in many locations, form a key part of coastal flood and erosion protection schemes. For example, where salt marshes front a constructed sea wall, in what might be referred to as a 'hybrid' engineered and nature-based coastal protection scenario, the flood protection provided depends not only on the sea wall, but also, to some extent, on the width and elevation of the salt marsh.

To accurately model future changes in marsh extent, however, we need to improve our understanding of the influence of salt marsh substrate properties on salt marsh stability. Marsh stability is defined as the ability of marsh substrates to resist the erosive forces induced by waves, tides and storm surges, while also accreting at a rate which keeps pace with sea-level rise (Reed, 1995). This stability is thus in part dependent upon the hydrodynamic force acting on the marsh and also the resistance of both the marsh platform and margin to erosion. While many studies have assessed the hydrodynamic forces acting on salt marshes (e.g. Möller \& Spencer, 2002; Fagherazzi et al. 2006; Callaghan et al. 2010; Tonelli et al. 2010), and some have assessed the role of biological properties in stabilizing salt marsh substrates (e.g. Turner et al. 2001; Morris et al. 2002; Le Hir et al. 2007), very few have looked at substrate properties and how these might affect marsh stability. Similarly, the few studies which do characterise salt marsh and tidal flat substrate properties rarely measure these properties in the context of known erosion mechanisms (e.g. cliff undercutting, gravitational slumping; Allen, 2000; Mariotti \& Fagherazzi, 2013; Leonardi et al. 2018) and therefore do not enhance our knowledge of how substrate properties relate to marsh stability. Moreover, models simulating salt marsh change under different future climate forcing scenarios generally include an erodibility coefficient (e.g. Mariotti \& Carr, 2014), but, due to a lack of data, these coefficients are rarely related to measured geotechnical and sedimentological properties.

The determination of salt marsh substrate properties is thus key for accurately simulating future marsh extent and how the protection afforded by hybrid or nature-based coastal protection schemes may differ under future changes in climate forcing, such as changes in storminess or an increased base water level due to sea-level rise. In this study, we address this.

\section{Field site}

Tillingham marsh is located on the central section of the Dengie Peninsula, Essex, UK (Fig. 1) and the mature marsh has an elevation of 2.4-2.7 m Ordnance Datum Newlyn (ODN; Möller, 2006), where

\footnotetext{
${ }^{1}$ Department of Geography, University of Cambridge, Downing Place, Cambridge, CB2 3EN, United Kingdom

${ }^{2}$ GeoAnalytics and Modelling Group, British Geological Survey, Nicker Hill, Keyworth, Nottingham, NG12 5GG, United Kingdom

${ }^{3}$ ARUP, 8-13 Fitzroy St, Bloomsbury, London, W1T 4BQ, United Kingdom
} 
$0.0 \mathrm{~m}$ ODN approximates to UK mean sea-level. The marsh is fronted by mudflats (0.9-1.4 m ODN; Pye \& French, 1993), which extend approximately four kilometers offshore (Möller \& Spencer, 2002). Shore-normal ridge-runnel morphology at the marsh-mudflat transition (Environmental Futures, 2003; Möller, 2006) likely reflects an eroding coast (Greensmith \& Tucker, 1975). The eroding phase of the past $c a$. 40 years seems to be part of longer-term dynamic behavior of the Dengie marshes over the past 100-150 years, with various studies having noted advancing and retreating phases (Greensmith \& Tucker, 1965; Harmsworth \& Long, 1986; Pye, 2000). In recent decades, this lateral marsh erosion has occurred alongside vertical marsh accretion, which has allowed the marsh to track sea-level rise (Reed, 1988; Callaway et al. 1996; van der Wal \& Pye, 2004).

The mid-marsh (>2.5 m ODN) is composed of Puccinellia maritima, Limonium vulgare and Atriplex portulacoides (Möller, 2006), with Elymus athericus along some creek margins. Pioneer/low marsh communities occur $\leq 2.5 \mathrm{~m}$ ODN (Rupprecht et al. 2015), often comprising Spartina anglica, Salicornia spp., Suaeda maritima and Aster tripolium (Möller, 2006).

Tillingham marsh is an open coast marsh with a large fetch (>100 km from Easterly directions). The Mean Spring Tide Range of $4.8 \mathrm{~m}$ results in a macrotidal regime (Reed, 1988). Möller \& Spencer (2002) recorded water depths of 0.12-0.84 m and mean (maximum) significant wave heights of 26 (86) $\mathrm{cm}$ at the vegetated marsh edge (2.4 m ODN) and in water depths of up to $1.95 \mathrm{~m}$ between September 2000 and July 2001. Current relative sea-level rise for the Dengie Peninsula is thought to be 2-3mm $\mathrm{yr}^{-1}$ (Burningham \& French, 2011), which includes eustatic components alongside regional land subsidence. This, combined with local geomorphic setting and coastal ecosystems (see Spencer et al. 2014) may exacerbate storm surge impacts.

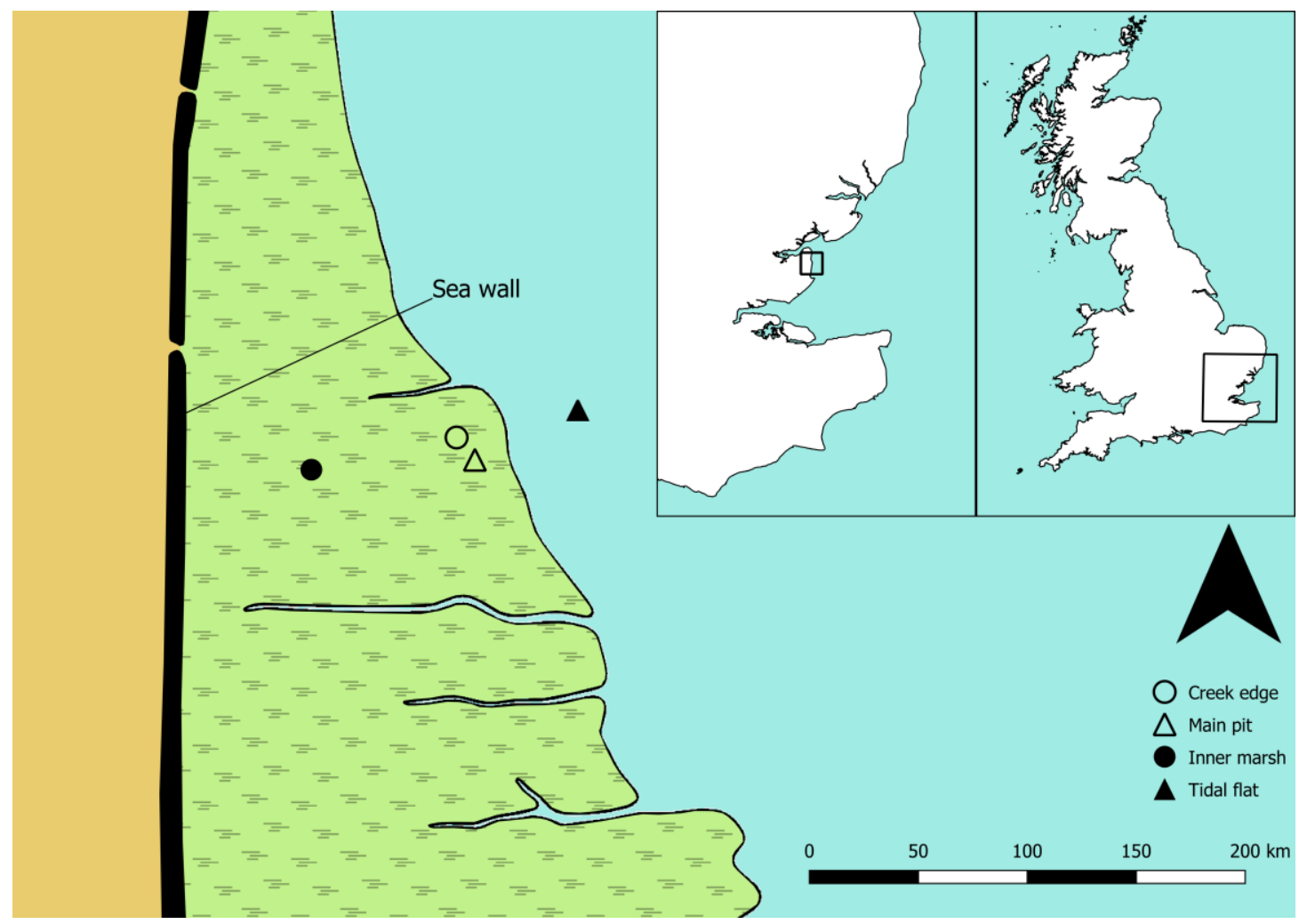

Figure 1: Site map of Tillingham marsh, Dengie Peninsula, Essex. The main map depicts the four core sites, located at: the marsh edge (hollow triangle), tidal flat (filled triangle), creek edge (hollow circle) and inner marsh (filled circle). Using: EDINA Digimap Ordnance Survey Service: https://digimap.edina.ac.uk/ Open Map Local [TIFF], Tile TM00, Downloaded Nov 2018. Contains OS data, Crown Copyright, under Digimap licence 2018.

\section{METHODS}

Four sites within the Tillingham marshes were selected for sediment coring, with an aim to capture any potential variation in substrate composition (particle size analysis and loss on ignition) and substrate behavior (shear box tests and consistency limit tests). These sites were located $20 \mathrm{~m}$ from the ridge-runnel morphology at the marsh edge (hereafter referred to as the 'main site'), on the tidal flat, at the edge of a large creek and in the inner marsh respectively (Fig. 1). Cores were obtained by using a 
gouge corer to penetrate the initial $50 \mathrm{~cm}$, followed by samples taken with a Russian corer up to 250$270 \mathrm{~cm}$ depth. Cores were packed in piping and Bubble $\mathrm{Wrap}^{\mathrm{TM}}$, to prevent disturbance, and refrigerated at $5^{\circ} \mathrm{C}$ upon return from the field.

Class 1 undisturbed geotechnical samples (200 mm x $200 \mathrm{~mm} \times 100 \mathrm{~mm}$ ) were taken from the main site, not far from the marsh edge, in accordance with BSI (2015). All undisturbed samples were taken between 0-30 cm depth. Samples were placed on trays, and wrapped in Bubble Wrap ${ }^{\mathrm{TM}}$ to minimize disturbance during transport to the laboratory. Bulk samples for consistency limits were also taken at the main site, at 0-10 cm, 10-20 cm and 20-30 cm depth. Both undisturbed and bulk samples were stored in a refrigerator at $5^{\circ} \mathrm{C}$, then described in accordance with BS 5930 (BSI, 2015).

Cores were sub-sampled at $5 \mathrm{~cm}$ intervals for loss on ignition (LOI) and particle size analysis in the laboratory of the Department of Geography, University of Cambridge. LOI methods followed BS 1377-3 (BSI, 1990a), leaving the samples in a muffle furnace at $440^{\circ} \mathrm{C}$ overnight. Samples for particle size analysis were pre-treated with $>30 \% \mathrm{w} / \mathrm{v}$ hydrogen peroxide overnight to remove organic matter, and then heated to $90^{\circ} \mathrm{C}$ in a water bath for two hours to ensure complete removal of organics. Samples were centrifuged and supernatant water was decanted, before adding $4.4 \%$ concentration sodium hexametaphosphate as a deflocculating agent. Samples were analysed using a Malvern Mastersizer 2000. Particle sizes were presented following Wentworth (1922), where sand refers to particle sizes > $63 \mu \mathrm{m}$, silt to those $<63 \mu \mathrm{m}$ and clay to sizes $<3.9 \mu \mathrm{m}$. Particle size and LOI analysis was also undertaken at all sample locations to complement shear box and consistency limit tests.

Shear box and consistency limit tests were undertaken in the British Geological Survey laboratories. The larger undisturbed field samples were subsampled to fit a $100 \mathrm{~mm}$ x $100 \mathrm{~mm}$ x $20 \mathrm{~mm}$ shear box, and the method was followed in accordance with BS 1377-7 (BSI, 1990b). Although the samples were surface samples, the applied normal load was restricted by the minimum load which could be applied to the shear box. Relatively low normal loads $\left(\sigma_{\mathrm{n}}\right)$ were applied to the specimen, starting at $10 \mathrm{kPa}$ for the first specimen, then increasing to $20 \mathrm{kPa}$ and $40 \mathrm{kPa}$ for the second and third specimens, representing $1 \mathrm{~m}, 2 \mathrm{~m}$ and $4 \mathrm{~m}$ water overburden, or approximately $0.5 \mathrm{~m}, 1 \mathrm{~m}$ and $2 \mathrm{~m}$ sediment overburden, respectively. Each test stage was sheared at a rate defined by $\mathrm{T}_{100}$ (the time at which $100 \%$ consolidation would occur, if primary consolidation continued; Bishop \& Henkel, 1962), keeping the displacement rate sufficiently slow to allow drainage. As such, we could assume zero pore water pressure and constant normal effective stress, $\sigma_{\mathrm{n}}$, throughout each test. Peak shear strengths for each specimen were then plotted to produce a failure envelope defined by the Mohr-Coulomb equation:

$$
\tau_{f}=c^{\prime}+\sigma_{n}^{\prime} \tan \varphi^{\prime}(\text { Equation 1) }
$$

where: $\tau_{\mathrm{f}}=$ shear strength, $\mathrm{c}^{\prime}=$ effective cohesion, $\sigma_{\mathrm{n}}{ }^{\prime}=$ normal effective stress, $\varphi^{\prime}=$ internal friction angle.

Bulk samples for determining consistency limits were wet sieved through a $425 \mu \mathrm{m}$ sieve to remove roots, in accordance with BS 1377-2 (BSI, 1990c). This ensured that cone penetrations were more repeatable, and also prevented roots from retaining moisture and affecting the moisture content. The liquid limit test was performed using the four point cone penetrometer method, following BS 13772 (BSI, 1990c), incrementally adding distilled water and testing the depth of cone penetration. The plastic limit test was also carried out in accordance with BS 1377-2 (BSI, 1990c).

\section{RESULTS}

Based on BS 5930 (BSI, 2015), the substrate was a very soft dark brown clayey silt with rootlets and lenses of clay. LOI fluctuates between $1.5 \%$ and $15 \%$ in the upper part of the core $(<50 \mathrm{~cm}$ depth) at each site (Fig. 2a), and decreases with depth. At the main site, tidal flat and inner core, the LOI falls to very low values $(<3 \%)$ at the base of the core. In general, LOI decreases with depth in the cores on the marsh, although this is not the case on the tidal flat. There was no difference in sediment composition between the cores taken at each site.

Throughout the majority of the cores the sediment is composed of silt (40-60\%), with clay (25$45 \%$ ) and sand (<10\%) (Fig. 2b). Particle size distributions vary between samples within a core and show no consistent trend downcore. An increase in sand and decrease in clay at the base of the core from the main site, tidal flat and inner site coincides with the observed decrease in LOI with depth.

Stress-strain curves from the shear box test demonstrate that the substrate at Tillingham behaves in a ductile manner (Fig. 3a). The Mohr-Coulomb failure envelope suggests a cohesive strength (c') of $2.15 \mathrm{kPa}$ and a friction angle ( $\varphi$ ') of 35 (Fig. $3 \mathrm{~b}$ ).

The consistency limits demonstrate that the sediment is composed of highly and very highly plastic clays and that the plasticity index decreases with depth (Fig. 4). 


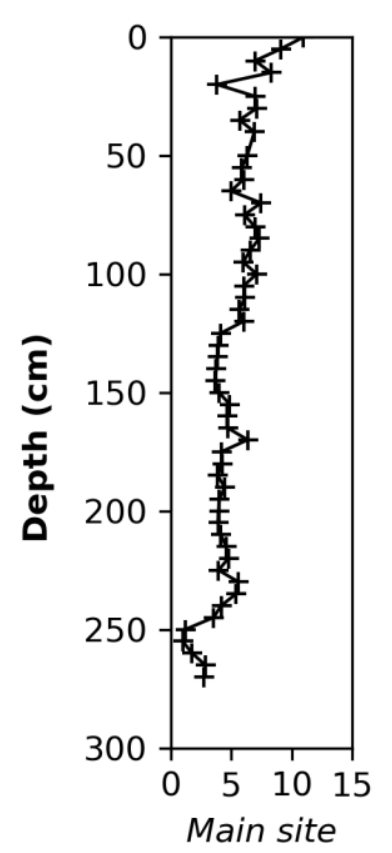

\section{(a) Loss on ignition}
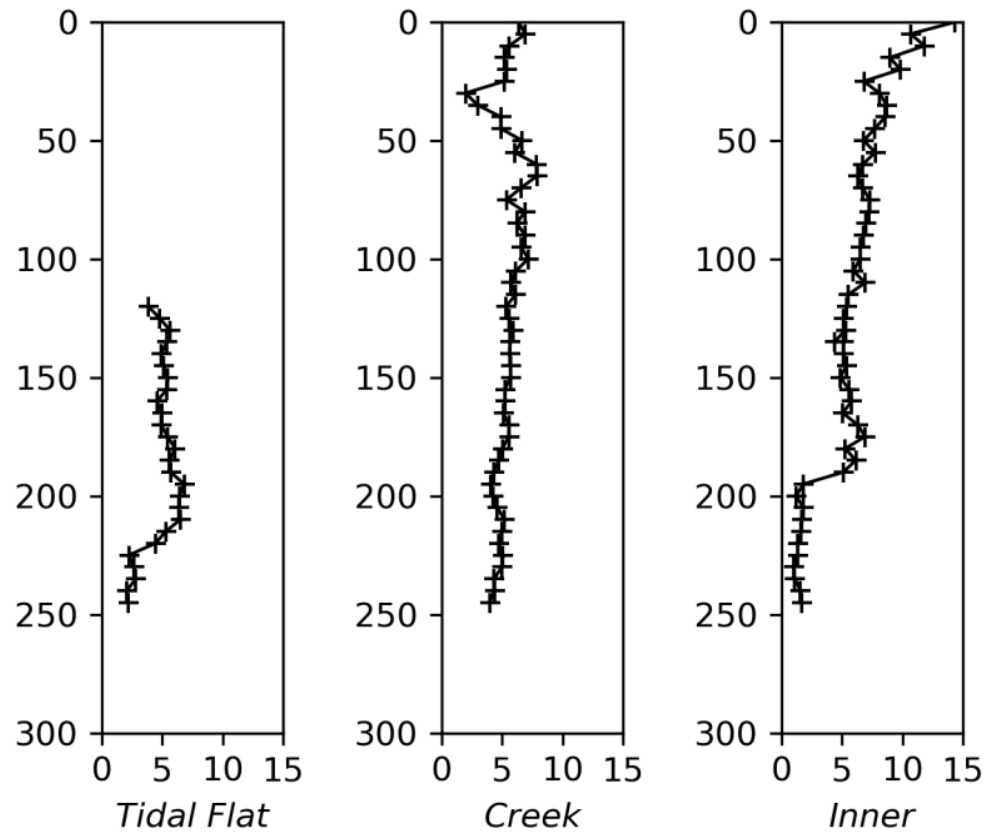

LOI (\%)

(b) Particle Size Analysis
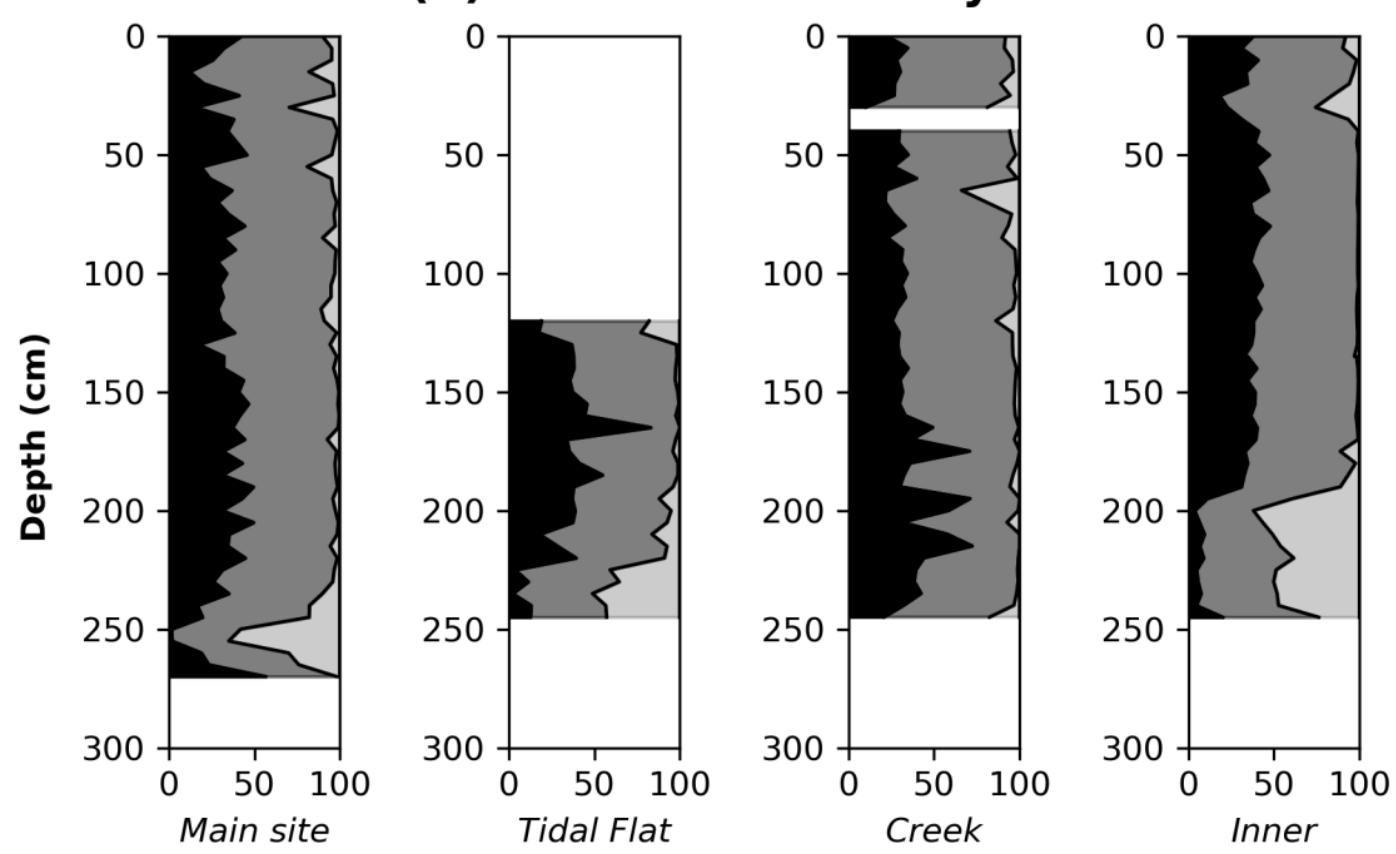

Cumulative clay/silt/sand (\%)

Figure 2: LOI (a) and particle size analysis data (b) for the main site, tidal flat, creek and inner marsh. The tidal flat data is adjusted to show the relative difference in elevation of the tidal flat surface, compared to the main site (the tidal flat surface is approximately $1.2 \mathrm{~m}$ lower). Particle size analysis graphs depict the cumulative percentage of clay (black shading), clay and silt (dark gray shading), and clay, silt and sand (the latter amounting to $100 \%$; light gray shading). Due to sampling issues, no particle size analysis sample was taken at $35 \mathrm{~cm}$ depth in the creek core. 


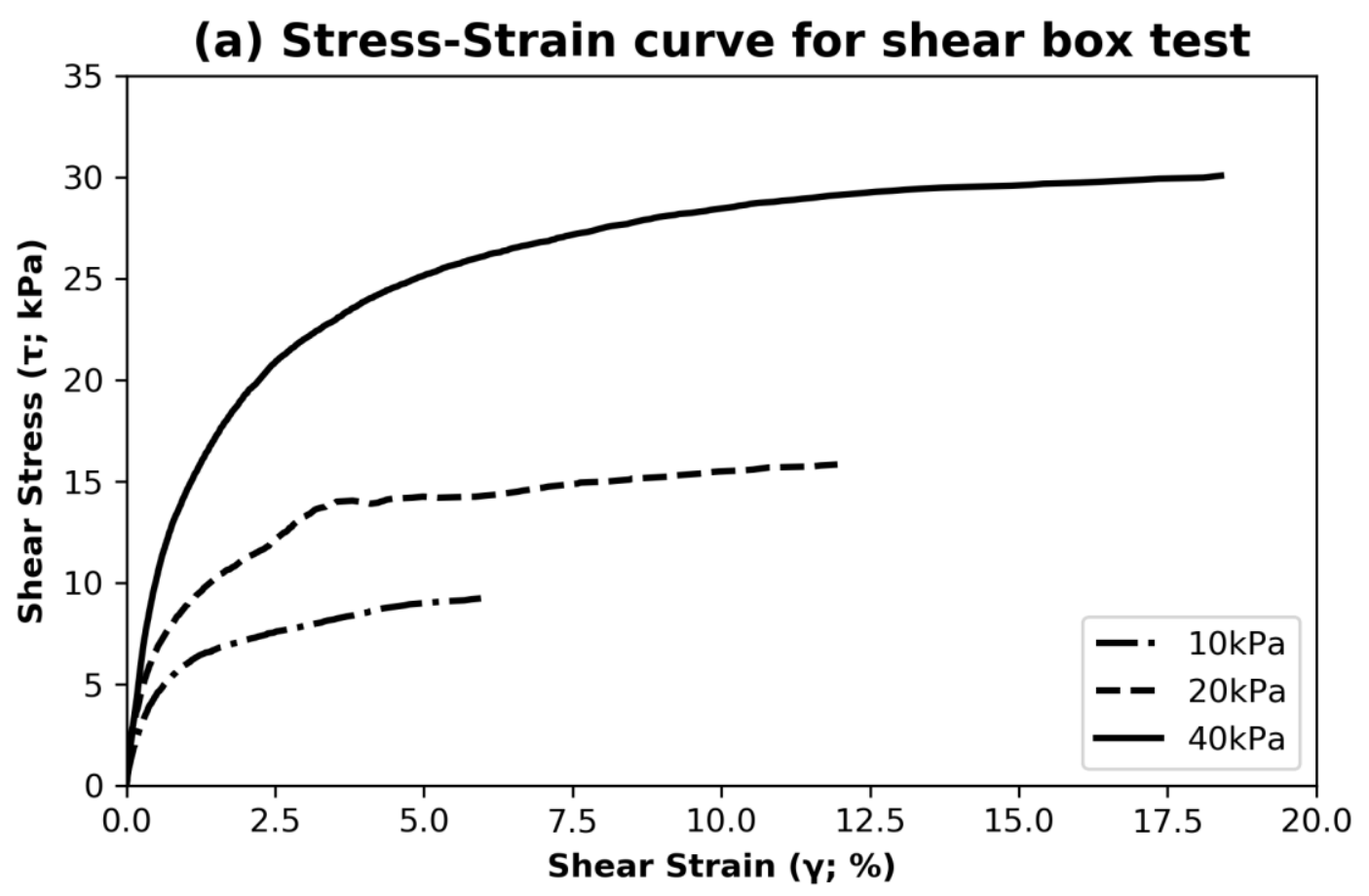

(b) Mohr-Coulomb Failure envelope for shear box test

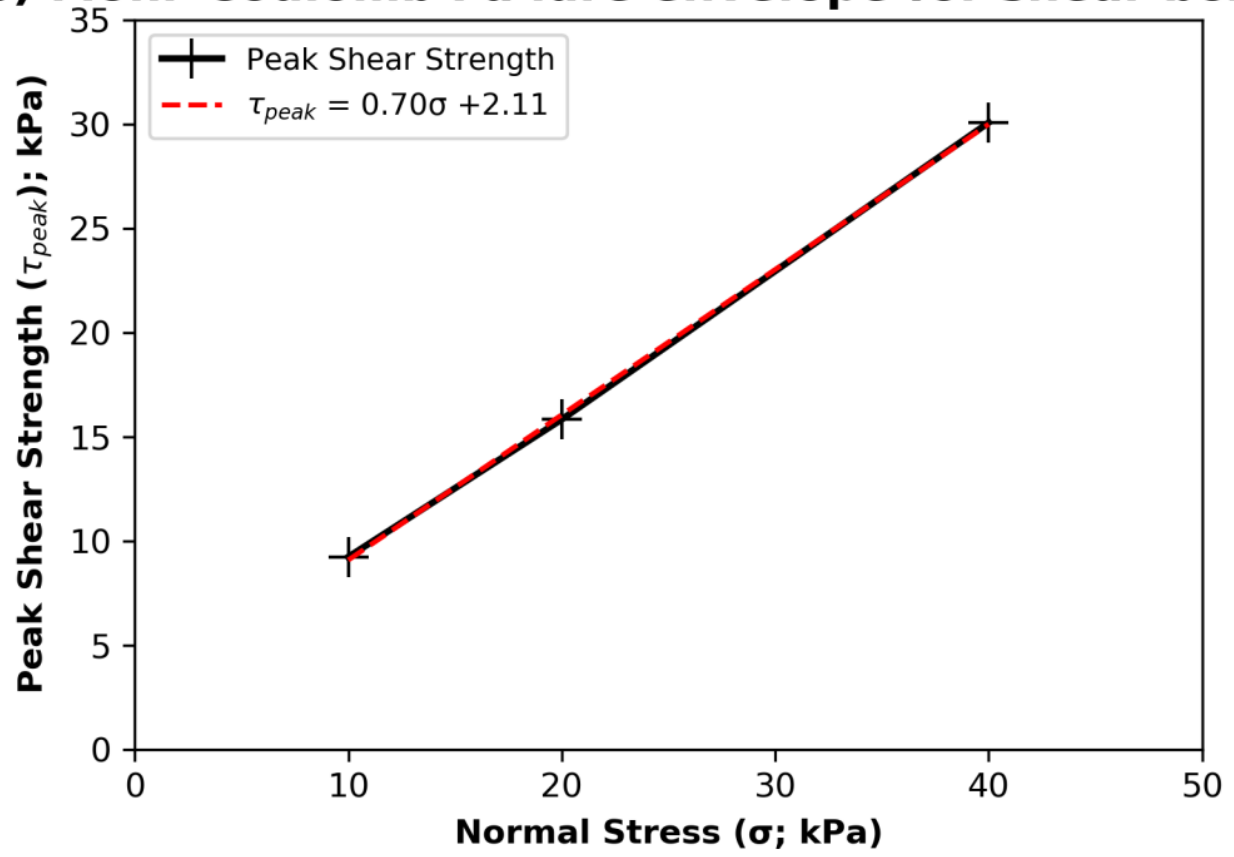

Figure 3: Stress-strain curves for samples from 0-30 cm depth, under $10 \mathrm{kPa}, 20 \mathrm{kPa}$ and $40 \mathrm{kPa}$ normal stress (a). The Mohr-Coulomb failure envelope (b) allowed quantification of the internal friction angle $\left(\varphi^{\prime}\right)$ and cohesive strength ( $\left.c^{\prime}\right)$ of the material. 


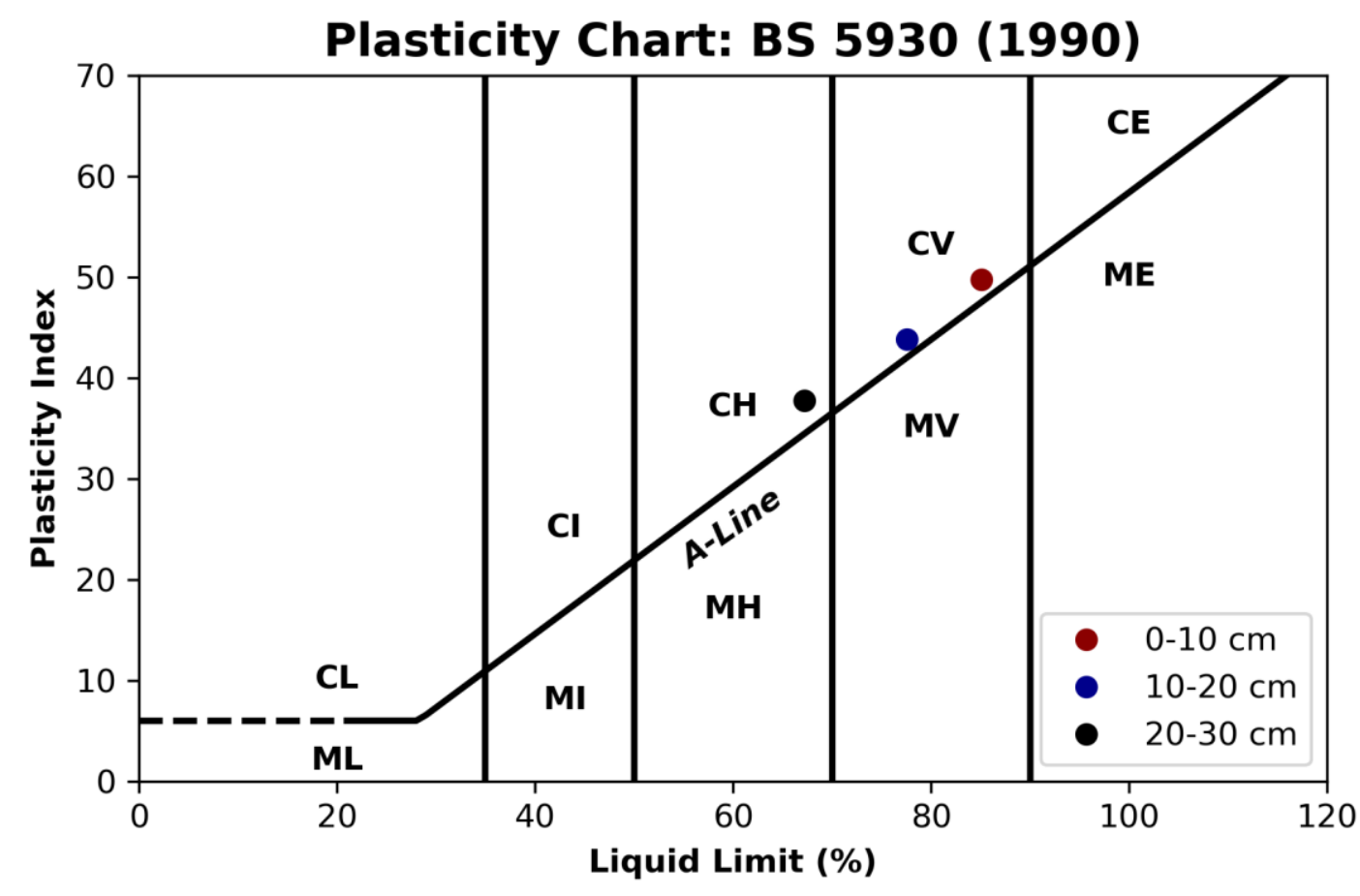

Figure 4: Plasticity chart for salt marsh samples at $0-10 \mathrm{~cm}, 10-20 \mathrm{~cm}$ and $20-30 \mathrm{~cm}$ depth, drawn in accordance with BS 5930 (BSI, 2015). The letters on the graph break the graph into sections to denote the behavior and plasticity of each sample, where $\mathbf{C}=$ clay-type behavior, $\mathbf{M}=$ silt-type behavior, $\mathbf{L}=\mathrm{low}$ plasticity, I = intermediate plasticity, $\mathrm{H}=$ high plasticity, $\mathrm{V}=$ very high plasticity, $\mathrm{E}=$ extremely high plasticity.

\section{DISCUSSION}

The substrate was silt-dominated, with a secondary clay component and a small sand component (Fig. 2b). While there appeared to be no considerable difference in sediment composition between the cores, further research will assess whether there are inter-site differences between sediment compositions in the uppermost part of the cores and then at specific depth ranges below the surface.

Increased sand content at the base of the core, in conjunction with reduced LOI (Fig. 2) likely reflects a different environment at the time of deposition. A sandy marsh base has been noted by other authors (e.g. Schuerch et al. 2012), and may relate to the start of marsh development. Given the exposed nature of the Tillingham marshes, it is conceivable that sandy substrate may have dominated the shore at the time at which the base of the core was deposited.

Throughout the core, there are layers with a relatively larger sand fraction, particularly at the main site and creek site (Fig. 2b). These may be storm deposits, which are known to consist of coarser material washed over marsh surfaces during relatively high wave energy events (Turner et al. 2006; Gedan et al. 2009; Schuerch et al. 2012). However, these layers are not found at the inner marsh site, possibly reflecting the fact that sediment transported by storm surges or higher energy events may not have reached the back of the marsh, or at least not in quantities large enough to be preserved in the stratigraphic record. Alternatively, the absence of these coarser deposits might reflect their patchy nature, whereby creeks might be important in funneling water currents and thus sediment prior to their overtopping and the deposition of coarser material on marsh surfaces. The fact that these layers are absent in the tidal flat core could be explained by the resuspension of sediment from the tidal flat during storms, as noted by Fagherazzi \& Wiberg (2009) and Tonelli et al. (2010). In some cases, this resuspended tidal flat sediment has been shown to be subsequently redeposited on the marsh (Mariotti \& Fagherazzi, 2010).

The substrate sampled at the main site had ductile behavior, so the material required continual stress application during the test to allow deformation (Fig. 3). This implies that, if the substrate were to reach a cliffed marsh edge or creek bank, any failure of material would occur in a ductile manner and there would not be immediate, catastrophic failure. While marsh edge failures could result in block failure, it is likely that these would remain partially joined to the marsh for some time, perhaps only becoming fully separated from the marsh through continual scouring and erosion of the point of contact to the main marsh platform. At present there is no cliff at the Tillingham marsh edge, so such failures 
would only occur in creeks, however the data presented here will provide a valuable comparison to other, cliffed, marsh sites, such as Bridgewick marsh, 2-3 km further South on the Dengie Peninsula (see Möller \& Spencer, 2002).

The measured cohesional strength and angle of internal friction (Fig. 3b) denote a cohesionless uniform medium fine or silty sand (Hoek \& Bray, 1974). This agrees with the particle size data, which showed the sediment to be composed of primarily silt, however contrasts with the clay-like behavior that is indicated when plotting the plasticity index against the liquid limit (Fig. 4).

While sediment consisted predominantly of silt-sized particles, the consistency limit tests demonstrate that the sediment does not behave as might be expected of silty substrates. Although the points in Fig. 4 plot close to the A-line, they depict clay-type behavior. This is an important observation, as particle size analysis is one of the main methods used to define sediment properties in salt marsh substrates to date. While in the civil engineering literature, it is customary to undertake plastic and liquid limit tests for fine-grained sediments (defined as $>35 \%$ clay and silt; Head, 1980), there is still an overreliance on particle size distribution for intertidal environments, with the exception of a very small number of studies (e.g. Crooks \& Pye, 2000; Brain et al. 2011; Chatagnier, 2012). To accurately understand how sediment properties affect salt marsh stability, a more appropriate and comprehensive approach to substrate description is likely needed, incorporating both substrate composition and behavioral properties.

In situ moisture content exceeded the plastic limit but was below the liquid limit (Table 1). Therefore, at the time of sampling, the substrate could be expected to behave plastically and neither catastrophic failure nor flows are expected. This agrees with the shear box results and further demonstrates that catastrophic failures are unlikely. Nevertheless, the intertidal nature of the environment means that moisture content in the field is likely to vary considerably depending on time within the spring-neap and daily tidal cycle, and antecedent moisture conditions (e.g. precipitation).

The liquid limits, plastic limits and plasticity indices measured at Tillingham are considerably lower than those found in other active salt marsh sediments in Essex (Table 1; Crooks \& Pye, 2000). The results presented here in the Tillingham marshes, however, are not dissimilar to those reported for reclaimed and former reclaimed salt marsh sediments on the Essex coast. For example, the liquid limit and plasticity index in the $0-10 \mathrm{~cm}$ sample at Tillingham are very similar to those measured by Crooks \& Pye (2000) in former reclaimed marsh sediments at Northey Island and North Fambridge (Table 1). The lower plasticity index in the deeper, $20-30 \mathrm{~cm}$ Tillingham sample is more comparable to that measured on reclaimed sediments at Tollesbury marsh, however the liquid limit in the Tillingham sample is more similar to those measurements from the Severn estuary sites by Crooks \& Pye (2000). While it is difficult to draw useful comparisons from these datasets at present, the data highlight considerable variability in salt marsh substrate behavioral properties. Unfortunately, incomplete particle size data from Crooks \& Pye (2000) limits our ability to coherently compare and understand the main influential properties on the plasticity index, such as the role of the clay fraction.

In comparison to samples from Greatham Creek in North East England (Brain et al. 2011), the Tillingham samples have approximately $20 \%$ lower organic content (Table 1). While both locations are silt-dominated, Tillingham has a comparatively larger clay fraction, while Greatham Creek has a larger sand fraction. At Tillingham, both the liquid limits and plastic limits were lower, but the plasticity index measured by Brain et al. (2011) was within the range found at Tillingham. While we would expect plasticity index to increase as clay fraction increases (Skempton, 1953), this appears to not always be the case. One possible explanation for this could be differences in clay mineralogy, warranting further research to explore this hypothesis.

Based on the liquid limit and plasticity index, the clay mineralogy may comprise a mixture of kaolinite and illite, with a larger illite component in the $0-10 \mathrm{~cm}$ sample, but a greater kaolinite component in the 20-30 cm sample. This would agree with Crooks \& Pye (2000), who assess clay mineralogy of southern Essex sites, finding predominantly smectite (41\%) and illite (41\%), with a lower proportion of kaolinite $(14 \%)$. However, when calculating the activity (plasticity index $\div$ percentage clay fraction), all three samples are defined as 'active clays' (see Day, 2001), thus implying that montmorillonite may be present. In comparison, the samples in Brain et al. (2011) have a higher activity, which potentially implies greater montmorillonite content. Although the consistency limits allow identification of the probable clay minerals present, clay mineralogy data could greatly enhance the interpretation of why the consistency limits vary between samples and between sites. 


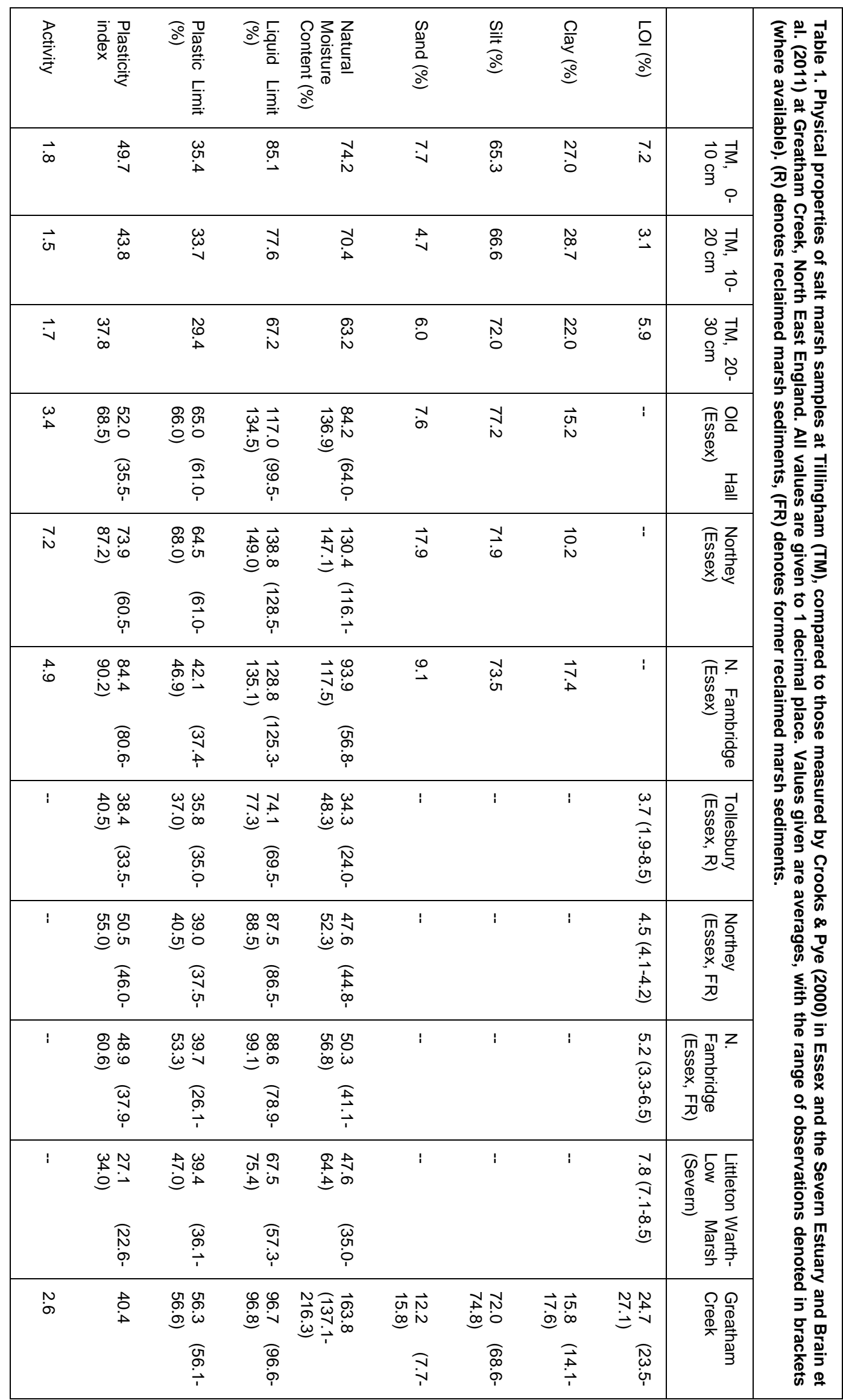


The above comparisons demonstrate considerable variability in marsh substrate behavior between sites within the UK. This study paves the way for a larger comparative study between substrate properties, incorporating particle size analysis, LOI, consistency limits, shear strength tests and consolidation tests. By comparing in-depth sedimentological and geotechnical data to both vertical and lateral changes in salt marshes, such a study has the potential to greatly improve models of future salt marsh extent on coasts on which both natural and re-created marshes (e.g. within managed realignment sites) are present.

\section{CONCLUSIONS}

Our study reports the initial results of a comprehensive project looking at geotechnical measurements of Northwestern European salt marsh and tidal flat sediments (particle size, plasticity and undrained shear strength). Discerning both salt marsh substrate composition and behavior is important for understanding the resistance of salt marshes to hydrodynamic forcing. With an enhanced understanding of salt marsh resistance, we can improve models of future salt marsh extent, taking into account the roles of potential changes in storminess and higher base water levels due to sea-level rise. As more data becomes available, this research will inform assessments of marshes as natural coastal defense features.

\section{ACKNOWLEDGMENTS}

This work was funded by a NERC PhD studentship (LCAG/329; 2016-2020), and a Collaborative Award in Science and Engineering (CASE) partnership with the British Geological Survey (LCAG/352). The authors would also like to thank Elizabeth Christie, Ben Evans, Sam Bithell, James Pollard, Amy McGuire for their help with field work, and Matt Kirkham, Steve Boreham and Lee Jones for their help with laboratory work.

\section{REFERENCES}

Allen, J. R. L. (2000). Morphodynamics of Holocene salt marshes: A review sketch from the Atlantic and Southern North Sea coasts of Europe. Quaternary Science Reviews, 19(12), 1155-1231.

Bishop, A. \& Henkel, D. (1962). The measurement of soil properties in the triaxial test. (2nd Edition). London: Arnold, (pp.228).

Brain, M. J., Long, A. J., Petley, D. N., Horton, B. P. \& Allison, R. J. (2011). Compression behaviour of minerogenic low energy intertidal sediments. Sedimentary Geology, 233(1-4), 28-41.

British Standards Institute, (1990a). Part 3: Chemical and electro-chemical tests. BS 1377. London : British Standard Institution, pp.42.

British Standards Institute, (1990b). Part 7: Shear strength tests (total stress). BS 1377. London : British Standard Institution, pp.48.

British Standards Institute, (1990c). Part 2: Classification tests. BS 1377-2. London, British Standard Institution, pp.64.

British Standards Institute, (2015). Code of Practise for Ground Investigations. BS 5930. London : British Standard Institution, pp.318.

Burningham, H. \& French, J. (2011). Seabed dynamics in a lage coastal embayment: 180 years of morphological change in the outer Thames estuary. Hydrobiologia, 672(1), 105-119.

Callaghan, D. P., Bouma, T. J., Klaassen, P., van der Wal, D., Stive, M. J. F. \& Herman, P. M. J. (2010). Hydrodynamic forcing on salt-marsh development: Distinguishing the relative importance of waves and tidal flows. Estuarine, Coastal and Shelf Science, 89(1), 73-88.

Callaway, J. C., DeLaune, R. D. \& Patrick, W. H. (1996). Chernobyl 137Cs used to determine sediment accretion rates at selected northern European coastal wetlands. Limnology and Oceanography, 41(3), 444-450.

Chatagnier, J. (2012). The Biomechanics of Salt Marsh Vegetation Applied To Wave and Surge Attenuation. Unpublished Masters Thesis, Louisiana State University and Agricultural and Mechanical College, (pp.55).

Crooks, S., \& Pye, K. (2000). Sedimentological controls on the erosion and morphology of saltmarshes: implications for flood defence and habitat recreation. In: Pye, K. \& Allen, J. R. L. (Eds.), Coastal and Estuarine Environments: sedimentology, geomorphology and geoarchaeology. Geological Society, London, Special Publications, Vol. 175, pp.207-222.

Day, R. W. (2001). Soil Testing Manual. New York, NY: McGraw Hill, (pp.618).

Environmental Futures, (2003). Wetland valuation: State of the art and opportunities for further development. Proceedings of a workshop organised for the Environment. In L. Ledoux (Ed.), Proceedings of a workshop organised for the Environment Agency by Environmental Futures Ltd 
and CSERGE. Norwich, UK, (pp.1-125).

Fagherazzi, S., Carniello, L., D’Alpaos, L. \& Defina, A. (2006). Critical bifurcation of shallow microtidal landforms in tidal flats and salt marshes. Proceedings of the National Academy of Sciences, 103(22), 8337-8341.

Fagherazzi, S. \& Wiberg, P. L. (2009). Importance of wind conditions, fetch, and water levels on wavegenerated shear stresses in shallow intertidal basins. Journal of Geophysical Research: Solid Earth, 114(F3), 1-12.

Gedan, K. B., Silliman, B. R. \& Bertness, M. D. (2009). Centuries of human-driven change in salt marsh ecosystems. Annual Review of Marine Science, 1, 117-141.

Greensmith, J. T. \& Tucker, E. V. (1965). Salt Marsh Erosion in Essex. Nature, 206(4984), 606-607.

Greensmith, J. T. \& Tucker, E. V. (1975). Dynamic structures in the Holocene Chenier plain setting of Essex, England. In J. Hails \& A. Carr (Eds.), Nearshore sediment dynamics and sedimentation. (pp. 251-272). Chichester: John Wiley.

Harmsworth, G. C., \& Long, S. P. (1986). An assessment of saltmarsh erosion in Essex, England, with reference to the Dengie Peninsula. Biological Conservation, 35(4), 377-387.

Head, K. H. (1980). Manual of Soil Laboratory Testing, Volume 1: Soil Classification and Compaction Tests. London: Plymouth: Pentech Press, (pp.339).

Hoek, E. \& Bray, J. (1974). Rock Slope Engineering. London: The Institution of Mining and Metallurgy, Unwin Brothers Limited, (pp.309).

Le Hir, P., Monbet, Y. \& Orvain, F. (2007). Sediment erodability in sediment transport modelling: Can we account for biota effects? Continental Shelf Research, 27(8), 1116-1142.

Leonardi, N., Carnacina, I., Donatelli, C., Ganju, N. K., Plater, A. J., Schuerch, M. \& Temmerman, S. (2018). Dynamic interactions between coastal storms and salt marshes: A review. Geomorphology, 301, 92-107.

Mariotti, G. \& Carr, J. (2014). Dual role of salt marsh retreat: Long-term loss and short-term resilience. Water Resources Research, 50(4), 2963-2974.

Mariotti, G. \& Fagherazzi, S. (2010). A numerical model for the coupled long-term evolution of salt marshes and tidal flats. Journal of Geophysical Research: Earth Surface, 115(F1), 1-15.

Mariotti, G. \& Fagherazzi, S. (2013). Critical width of tidal flats triggers marsh collapse in the absence of sea-level rise. Proceedings of the National Academy of Sciences of the United States of America., 110(14), 5353-5356.

Möller, I. (2006). Quantifying saltmarsh vegetation and its effect on wave height dissipation: Results from a UK East coast saltmarsh. Estuarine, Coastal and Shelf Science, 69(3-4), 337-351.

Möller, I. \& Spencer, T. (2002). Wave dissipation over macro-tidal saltmarshes: Effects of marsh edge typology and vegetation change. Journal of Coastal Research, 36(36), 506-521.

Morris, J, T., Sundareshwar, P. V., Nietch, C. T., Kjerfve, B. \& Cahoon, D. R. (2002). Responses of coastal wetlands to rising sea level. Ecology, 83(10), 2869-2877.

Pye, K. (2000). Saltmarsh erosion in southeast England: mechanisms, causes and implications. In B. R. Sherwood, B. G. Gardiner, \& H. T (Eds.), British Saltmarshes. Cardigan/London, (pp.359-396).

Pye, K. \& French, J. (1993). Erosion and Accretion Processes on British Salt marshes: Final report to MAFF (5 Volumes). Cambridge.

Reed, J. (1988). Sediment Retreating Dynamics and Deposition in a Retreating Coastal Salt Marsh. Estuarine, Coastal and Shelf Science, 26(1), 67-79.

Reed, D. J. (1995). The Response of Coastal Marshes To Sea-Level Rise: Survival or Submergence? Earth Surface Processes and Landforms, 20(1), 39-48.

Rupprecht, F., Möller, I., Evans, B., Spencer, T. \& Jensen, K. (2015). Biophysical properties of salt marsh canopies - Quantifying plant stem flexibility and above ground biomass. Coastal Engineering, 100, 48-57.

Schuerch, M., Rapaglia, J., Liebetrau, V., Vafeidis, A. \& Reise, K. (2012). Salt Marsh Accretion and Storm Tide Variation: An Example from a Barrier Island in the North Sea. Estuaries and Coasts, 35(2), 486-500.

Skempton, A. W. (1953). The Colloidal "Activity” of Clays. In ICOSOMEF (Ed.), Proceedings of the 3rd International Conference on Soil Mechanics and Foundation Engineering, Zurich, (pp.6177).

Spencer, T., Brooks, S. M., Möller, I. \& Evans, B. R. (2014). Where local matters: Impacts of a major north sea storm surge. Eos, 95(30), 269-270.

Tonelli, M., Fagherazzi, S. \& Petti, M. (2010). Modeling wave impact on salt marsh boundaries. Journal of Geophysical Research: Oceans, 115(C9), 1-17.

Turner, R. E., Swenson, E. M. \& Milan, C. S. (2001). Organic and inorganic contributions to vertical 
accretion in salt marsh sediments. In M. Weinstein \& K. Kreeger (Eds.), Concepts and Controversies in Tidal Marsh Ecology (pp. 583-595). Dordrecht, Netherlands: Kluwer Academic Publishers.

Turner, R. E., Baustian, J. J., Swenson, E. M. \& Spicer, J. S. (2006). Wetland Sedimentation from Hurricanes Katrina and Rita. Science, 314(5798), 449-452.

van der Wal, D. \& Pye, K. (2004). Patterns, rates and possible causes of saltmarsh erosion in the Greater Thames area (UK). Geomorphology, 61(3-4), 373-391.

Wentworth, C. K. (1922). A scale of grade and class terms for clastic sediments. The Journal of Geology, 30(5), 372-392. 